Diabetologia (1994) 37:252-256

\title{
Glycated haemoglobin predicts progression to diabetes mellitus in Pima Indians with impaired glucose tolerance
}

\author{
R.R. Little ${ }^{1,2}$, J.D.England ${ }^{2}$, H. M. Wiedmeyer ${ }^{2}$, R. W. Madsen ${ }^{3}$, D.J. Pettitt ${ }^{4}$, W. C. Knowler ${ }^{4}$, D. E. Goldstein ${ }^{1,2}$ \\ ${ }^{1}$ Department of Pathology, University of Missouri, School of Medicine, Columbia, Missouri, USA \\ ${ }^{2}$ Department of Child Health, University of Missouri, School of Medicine, Columbia, Missouri, USA \\ ${ }^{3}$ Department of Statistics, University of Missouri, School of Medicine, Columbia, Missouri, USA \\ ${ }^{4}$ Diabetes and Arthritis Epidemiology Section, National Institute of Diabetes and Digestive and Kidney Diseases, Phoenix, \\ Arizona, USA
}

Summary Glycated haemoglobin could offer several practical advantages over the OGTT for assessing glucose metabolism. Initial cross-sectional studies (19831985) on 381 subjects (mostly Pima Indians) described the relationship between $\mathrm{HbA}_{1 c}$ (a specific glycated $\mathrm{Hb}$ ) and the OGTT. We performed follow-up OGTTs and $\mathrm{HbA}_{1 \mathrm{c}}$ measurements on 257 of these same subjects 1.6-6.1 years later. Subjects were again grouped according to both the result of the OGTT (normal, IGT or diabetes, by WHO criteria) and $\mathrm{HbA}_{1 \mathrm{c}}$ result (normal or elevated based on mean $\pm 1.96 \mathrm{SD}$ of normal). Of 66 subjects with IGT at baseline, 47 (71\%) had nor- mal $\mathrm{HbA}_{1 \mathrm{c}}$ and $19(29 \%)$ had elevated $\mathrm{HbA}_{1 \mathrm{c}}$. Twentysix $(39 \%)$ of these subjects had diabetes at follow-up. Of these subjects with IGT, a significantly greater percentage of subjects with elevated $\mathrm{HbA}_{1 \mathrm{c}}$ at baseline $(68 \%)$ showed worsening to diabetes than those with a normal $\mathrm{HbA}_{1 \mathrm{c}}(28 \%$ ); (chi-square $=7.8, d f=1$, $p<0.01$ ). Thus, in subjects with IGT, glycated Hb may be a useful predictor of progression to diabetes. [Diabetologia (1994) 37:252-256]

Key words Follow-up study, glycated $\mathrm{Hb}, \mathrm{HbA}_{1 \mathrm{c}}$, IGT, Pima Indians.
The OGTT is often used to diagnose diabetes mellitus as well as to detect more mildly impaired carbohydrate metabolism. Measurement of glycated $\mathrm{Hb}$ has been suggested as an alternative to the OGTT for assessing glucose metabolism [1-4]. The concentration of glycated $\mathrm{Hb}$ is increased within erythrocytes of patients in proportion to the degree of chronic hyperglycaemia; it is an indirect measure of the average blood glucose concentration over the previous 2 to 3 months [3]. Glycated $\mathrm{Hb}$ is widely used for monitoring long-term glycaemic control in known diabetic patients [5-8], and the prognostic value of glycated $\mathrm{Hb}$ has been investigated in a longitudinal study design of patients with normal glucose tolerance [9]. Measurement of glycated

Received: 8 February 1993

and in final revised form: 26 August 1993

Corresponding author: Dr. R.R. Little, Pathology Department M263, University of Missouri School of Medicine, One Hospital Drive, Columbia, MO 65212, USA
$\mathrm{Hb}$ offers some practical advantages over the OGTT; it is not influenced by time of day, recent activity levels, metabolic stress, or food intake [7]. Only minimal patient cooperation is required before and during the test, and only one small blood sample is required.

Our initial cross-sectional studies [4] described the relationship between $\mathrm{HbA}_{1 \mathrm{c}}$, a specific glycated $\mathrm{Hb}$, and OGTT. In 381 subjects (mostly Pima Indians) from a population with a high prevalence of non-insulin-dependent diabetes mellitus, $\mathrm{HbA}_{1 \mathrm{c}}$ had high specificity and moderate sensitivity as a screening test for diabetes defined by the OGTT using WHO criteria [4]. Here we re-examine these same individuals 1 to 6 years later to investigate the prognostic value of glycated $\mathrm{Hb}$. By using both OGTT and glycated $\mathrm{Hb}$ results, we attempted to identify, among a group of high risk subjects, those who are at greatest risk of developing diabetes.

\section{Subjects, materials, and methods}

Subjects. Subjects included 257 individuals residing in the Gila River Indian Community of central Arizona (USA) who were participating in a longitudinal epidemiologic study of diabetes 
R. R. Little et al.: $\mathrm{HbA}_{1 \mathrm{c}}$ predicts progression to diabetes

Table 1. Results of OGTT and $\mathrm{HbA}_{1 c}$ classification of 257 subjects at baseline and follow-up

\begin{tabular}{|c|c|c|c|c|c|c|}
\hline $\begin{array}{l}\text { Follow-up } \\
\text { (n) }\end{array}$ & $\begin{array}{l}\mathrm{N}-\mathrm{N} \\
(86)\end{array}$ & $\begin{array}{l}\text { N-Elev } \\
(6)\end{array}$ & $\begin{array}{l}\text { IGT-N } \\
(36)\end{array}$ & $\begin{array}{l}\text { IGT-Elev } \\
(16)\end{array}$ & $\begin{array}{l}\mathrm{D}-\mathrm{N} \\
(7)\end{array}$ & $\begin{array}{l}\text { D-Elev } \\
(106)\end{array}$ \\
\hline \multicolumn{7}{|l|}{ Baseline (n) } \\
\hline N-N (93) & 68 & 3 & 8 & 5 & 2 & 7 \\
\hline N-Elev (9) & 5 & 2 & 1 & 0 & 0 & 1 \\
\hline IGT-N (47) & 11 & 0 & 19 & 4 & 3 & 10 \\
\hline IGT-Elev (19) & 1 & 0 & 1 & 4 & 0 & 13 \\
\hline $\mathrm{D}-\mathrm{N}(14)$ & 1 & 1 & 5 & 1 & 2 & 4 \\
\hline
\end{tabular}

$\mathrm{N}-\mathrm{N}$, Normal glucose tolerance and normal $\mathrm{Hb} \mathrm{A}_{10}$; $\mathrm{N}$-Elev, normal glucose tolerance and elevated $\mathrm{HbA}_{1 c}$; IGT-N, IGT and normal $\mathrm{HbA}_{1 c}$;

and obesity conducted by the National Institute of Diabetes and Digestive and Kidney Diseases since 1965

Between 1983 and 1985, 381 subjects underwent a standard OGTT according to WHO recommendations in which plasma glucose concentrations were determined in the fasting state and $2 \mathrm{~h}$ after ingestion of a 75-g carbohydrate load (Glucola; Ames, Elkhart, Ind., USA). For purposes of the present study this was called the baseline visit. The sample was not representative of the total population but over represented people with IGT and diabetes. At the time of OGTT, a venous blood sample was obtained from each subject for measurement of $\mathrm{HbA}_{1 \mathrm{c}}$. This blood sample was placed in an insulated container with wet ice and shipped overnight to the Diabetes Research Laboratory of the University of Missouri at Columbia (USA) [10]. Results of the baseline visits have been reported previously [4].

Between 1985 and 1990,257 of these same individuals underwent at least one additional OGTT and $\mathrm{HbA}_{1 \mathrm{c}}$ determination 1 year or more after the baseline visit. This was designated the follow-up visit. For subjects with more than one follow-up visit, the most recent follow-up visit results were used in data analysis.

$O G T T$ classification. Each subject was classified according to WHO criteria as having normal glucose tolerance, IGT, or diabetes mellitus [11]. Diagnosis of diabetes requires a fasting plasma glucose of $7.8 \mathrm{mmol} / \mathrm{l}$ or greater or a 2 -h plasma glucose of $11.1 \mathrm{mmol} / \mathrm{l}$ or greater. Subjects are diagnosed as having IGT when fasting plasma glucose is less than $7.8 \mathrm{mmol} / \mathrm{l}$ and 2 -h plasma glucose is $7.8 \mathrm{mmol} / \mathrm{l}$ or greater and less than $11.1 \mathrm{mmol} / \mathrm{l}$. Individuals with a fasting and 2 -h plasma glucose of less than $7.8 \mathrm{mmol} / \mathrm{l}$ were considered to have normal glucose tolerance. Results of glucose tolerance tests performed prior to the baseline visit were not considered for purposes of this classification. However, individuals who were receiving insulin or oral hypoglycaemic therapy at the baseline visit were excluded.

Preparation of blood samples and analysis of $H b A_{1 \mathrm{c}}$. Details of sample preparation and analysis have been described previously $[4,12]$. Briefly, a haemolysate was prepared from washed and incubated erythrocytes and $\mathrm{Hb} \mathrm{A}_{1 \mathrm{c}}$ was measured by a component HPLC system which was calibrated at each run. Inter-assay coefficients of variation were 1.9 and $3.2 \%$ for quality control samples with mean values of 5.5 and $8.0 \%$, respectively during the time period of this study.

$H b A_{1 c}$ classification. Each $\mathrm{HbA}_{1 \mathrm{c}}$ result was classified as either normal or elevated based on whether it was below or above the upper limit of the $\mathrm{HbA}_{1 \mathrm{c}}$ normal range which was $6.03 \%$ (mean $+1.96 \mathrm{SD}$; mean $=5.05 \%, \mathrm{SD}=0.50 \%$ ). This range was determined for a mostly Caucasian population using 124 healthy volunteers at various centres throughout the United States, using the same assay method as described above. Although glucose tolerance tests were not performed on these subjects, all had
IGT-Elev, IGT and elevated $\mathrm{HbA}_{1 \mathrm{c}}$;

$\mathrm{D}-\mathrm{N}$, diabetes and normal $\mathrm{HbA}_{1 \mathrm{c}}$;

D-Elev, diabetes and elevated $\mathrm{Hb} \mathrm{A}_{\mathrm{Lc}}$

fasting plasma glucose values below $6.4 \mathrm{mmol} / \mathrm{l}$. Mean $\mathrm{HbA}_{1 \mathrm{c}}$ for the Pima Indians with normal glucose tolerance was somewhat higher $(n=159$, mean $=5.43 \%, \mathrm{SD}=0.40 \%)$.

$O G T T-H b A_{1 \mathrm{c}}$ grouping. Each of the 257 study subjects was placed in one of six groups which describe both the OGTT and $\mathrm{HbA}_{1 \mathrm{c}}$ classification at baseline (Table 1).

\section{Statistical analysis}

A chi-squared test was used to test for the difference in the rate of progression to diabetes between two IGT groups; those with normal vs those with elevated $\mathrm{HbA}_{1 c}$. Comparison of the proportion of subjects whose diabetes persisted at follow-up among those having an OGTT in the diabetic range at baseline (diabetes/normal $\mathrm{HbA}_{1 \mathrm{c}}$ vs diabetes/elevated $\mathrm{HbA}_{1 \mathrm{c}}$ ) was done using a two-tailed Fisher test. A multiple logistic regression model was used to investigate the relationship between several risk variables (e.g. $\mathrm{HbA}_{1 \mathrm{c}}$, 2-h plasma glucose) and progression to diabetes in subjects with IGT.

\section{Results}

Of the 381 subjects studied at baseline (142 men, 239 women), 257 ( 85 men, 172 women) had follow-up examinations. The mean age of the 257 study subjects at baseline was 46.7 years (range $15-87$ years). The mean time between baseline and follow-up exams was 3.3 years (range $=1.6-6.1$ years). At the baseline exam, $39.7 \%$ had a normal OGTT, $25.7 \%$ had IGT, and $34.6 \%$ had diabetes (i.e. fasting glucose of $7.8 \mathrm{mmol} / 1$ or greater or a 2-h glucose of $11.1 \mathrm{mmol} / \mathrm{l}$ or greater). At follow-up, $35.8 \%$ had normal glucose tolerance, $20.2 \%$ had IGT, and $44.0 \%$ had diabetes. The most common change was from IGT to diabetes, although there were changes into and out of every classification. At baseline $60 \%$ of subjects had a normal $\mathrm{HbA}_{1 \mathrm{c}}$ while $40 \%$ had an elevated $\mathrm{HbA}_{1 \mathrm{c}}$ value. At follow-up only $50 \%$ had $\mathrm{HbA}_{1 \mathrm{c}}$ values in the normal range.

Table 1 shows the number of subjects in each of six OGTT-HbA $A_{1 \mathrm{c}}$ groups (as defined in Subjects, materials and methods) at baseline and at follow-up. Of those subjects with a normal OGTT at baseline; 93 had a normal and nine had an elevated $\mathrm{HbA}_{1 \mathrm{c}}$ (Table 1). At fol- 


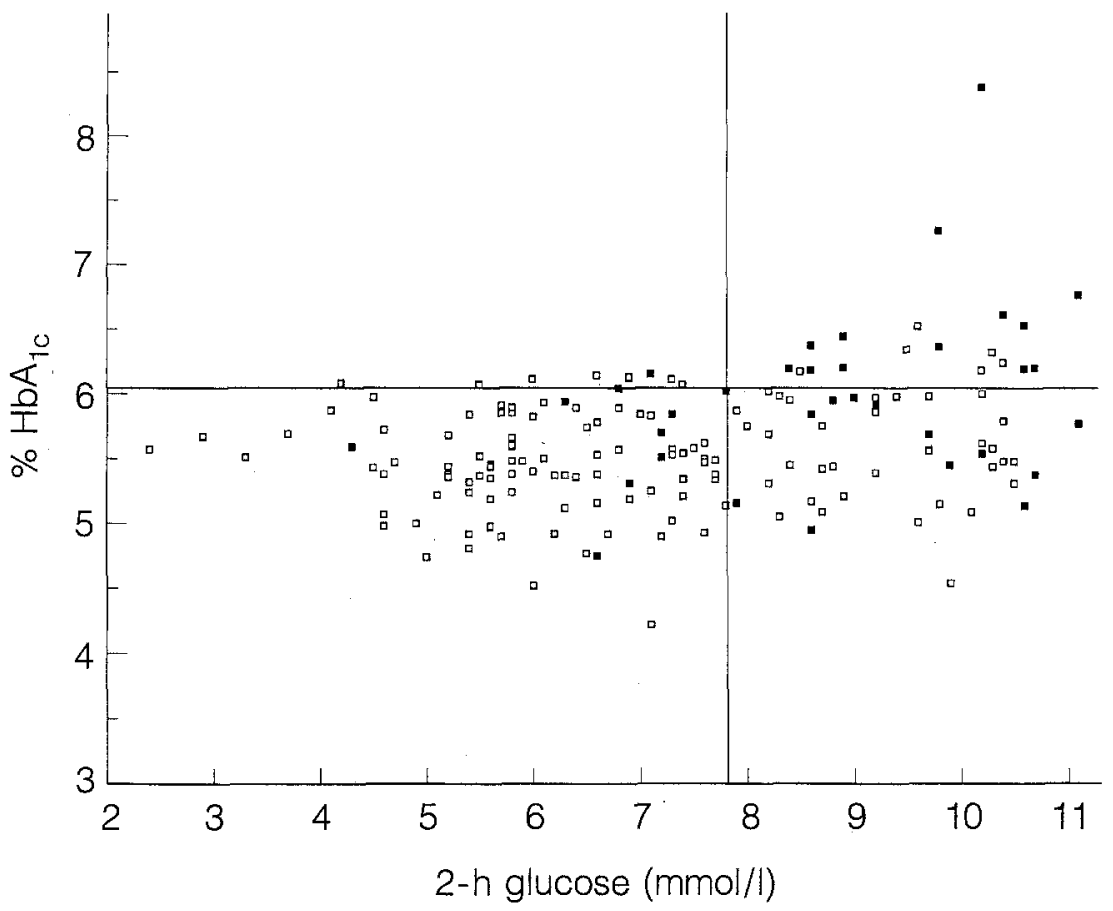

Fig.1. Relationship between baseline 2-h glucose and $\mathrm{Hb}_{1 \mathrm{c}}$ in those subjects who were non-diabetic at baseline. The horizontal line indicates the upper limit of normal values for $\mathrm{HbA}_{1 \mathrm{c}}(6.05 \%)$. The vertical line indicates the 2-h plasma glucose cutoff for IGT $(7.8 \mathrm{mmol} / \mathrm{l}) . \square$, subjects who were non-diabetic at follow-up; —, subjects who were diabetic at follow-up

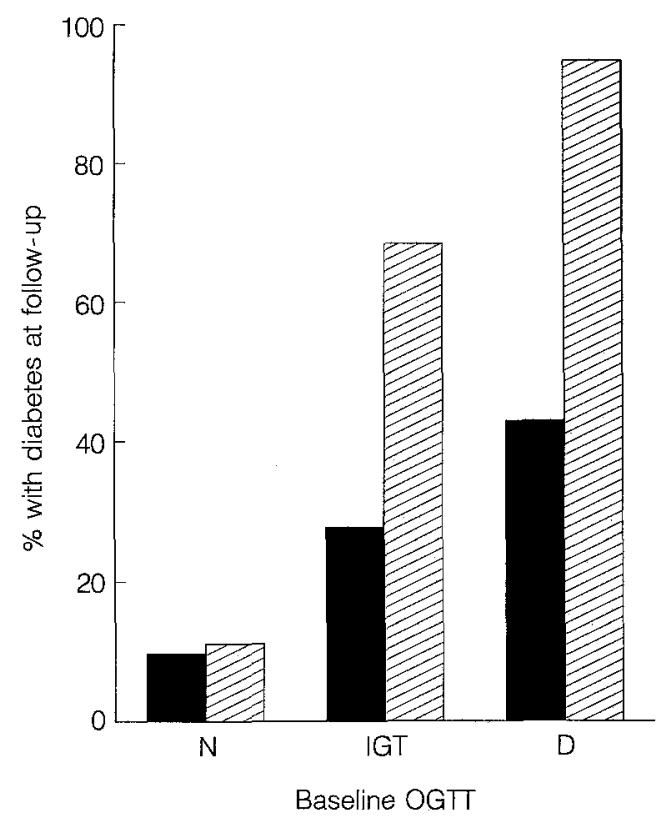

Fig. 2. Relationship between baseline $\mathrm{OGTT} / \mathrm{Hb} \mathrm{A}_{1 \mathrm{c}}$ group and prevalence of diabetes by WHO criteria at follow-up. N, normal glucose tolerance; IGT, impaired glucose tolerance; D, diabetes; $\boldsymbol{\square}$, normal $\mathrm{HbA}_{1 \mathrm{c}} ;, \boxminus$, elevated $\mathrm{HbA}_{1 \mathrm{c}}$

Table 2. Results of multiple logistic regression model in 66 subjects with IGT at baseline

\begin{tabular}{lll}
\hline $\begin{array}{l}\text { Dependent variable: } \\
\text { Variable }\end{array}$ & Odds & $95 \%$ confidence \\
& ratio & interval \\
\hline $\mathrm{HbA}_{1 \mathrm{c}}{ }^{\mathrm{a}}$ & 6.76 & $1.77-25.8$ \\
$\mathrm{Sex}^{\mathrm{b}}$ & 5.77 & $1.51-22.0$ \\
\hline
\end{tabular}

a Odds ratio for a $1 \%$ difference in $\mathrm{HbA}_{1 \mathrm{c}}$;

${ }^{\mathrm{b}}$ odds ratio for men to women low-up, the two $\mathrm{HbA}_{1 \mathrm{c}}$ groups had similar rates of IGT $\left(14.0 \%\right.$ in subjects with a normal $\mathrm{HbA}_{1 \mathrm{c}}$ and $11.1 \%$ in those with an elevated $\left.\mathrm{HbA}_{1 \mathrm{c}}\right)$ and of diabetes $(9.7 \%$ and $11.1 \%$, respectively). As shown graphically in Figure 1, it should be noted that all of the elevated $\mathrm{HbA}_{1 \mathrm{c}}$ values in this normal-OGTT group at baseline were only slightly elevated $\left(6.07-6.15 \% \mathrm{HbA}_{1 \mathrm{c}}\right)$. At followup, those in the normal-OGTT/elevated $\mathrm{HbA}_{1 \mathrm{c}}$ group were also only slightly elevated $\left(6.05-6.60 \% \mathrm{HbA}_{1 c}\right)$.

Of subjects with IGT at baseline, 47 had a normal and 19 an elevated $\mathrm{HbA}_{1 \mathrm{c}}$ (Table 1). Among those with a normal $\mathrm{HbA}_{1 \mathrm{c}}, 27.7 \%$ (13 of 47) progressed to diabetes during follow-up while among those with an elevated $\mathrm{HbA}_{1 \mathrm{c}}, 68.4 \%$ (13 of 19 ) progressed to diabetes (chisquare $=7.8, d f=1, p<0.01$ ). Of subjects with IGT and elevated $\mathrm{HbA}_{1 \mathrm{c}}$, in contrast to those with normalOGTT, $\mathrm{HbA}_{1 \mathrm{c}}$ values ranged widely from 6.17 to $8.37 \%$ (Fig. 1). Prevalence of diabetes at follow-up is shown in Figure 2 by OGTT/HbA $A_{1 c}$ group at baseline. In the 66 persons with IGT at baseline, the results of a multiple logistic regression analysis, with diabetes at follow-up as the binary outcome variable, are shown in Table 2 . In this analysis, $\mathrm{HbA}_{1 \mathrm{c}}$ was used as a continuous variable. With both $\mathrm{HbA}_{1 \mathrm{c}}$ and 2-h post-load plasma glucose in the model, $\mathrm{HbA}_{1 \mathrm{c}}$ was a significant predictor of subsequent diabetes while 2 -h glucose added little to the model. With sex and $\mathrm{HbA}_{1 \mathrm{c}}$ in the model, 2-h post-load plasma glucose concentration, age, body mass index, and the time between baseline and follow-up exams did not add to the predictive ability of the model. Controlled for sex, $\mathrm{HbA}_{1 \mathrm{c}}$ was still a significant predictor for the development of diabetes (odds ratio for having a $\mathrm{HbA}_{1 \mathrm{c}}$ concentration $1 \%$ higher $=6.76$, Table 2 ). Interestingly there was a significantly greater proportion of males than females that progressed to diabetes. 
Of subjects with diabetes at baseline, 14 had a normal and 75 an elevated $\mathrm{HbA}_{1 \mathrm{c}}$ (Table 1). At follow-up, $57 \%$ (8 of 14) of those with a normal $\mathrm{HbA}_{1 \mathrm{c}}$ at baseline had a 2 -h post-load plasma glucose concentration below $11.1 \mathrm{mmol} / \mathrm{l}$ including two $(14.3 \%)$ with a glucose below $7.8 \mathrm{mmol} / \mathrm{l}$. Less than one-half of these subjects would be classified as diabetic by OGTT at followup (43\%, Figs. 1,2$)$. By contrast, only $5.3 \%$ ( 4 of 75 ) of those with an elevated baseline $\mathrm{HbA}_{1 \mathrm{c}}$ had a 2-h glucose below $11.1 \mathrm{mmol} / \mathrm{l}$ (Fig. 2); almost $95 \%$ had an OGTT in the diabetic range at follow-up $(p<0.001$, two-tailed Fisher test).

\section{Discussion}

Previous studies have examined the relationship between glycated $\mathrm{Hb}$ and OGTT [1-3, 13-21]. Many of these studies have shown a good correlation between glycated $\mathrm{Hb}$ and either fasting or 2-h plasma glucose levels, but there has been considerable overlap of glycated $\mathrm{Hb}$ values in each OGTT category $[3,14,19,22$, 23]. In our previous cross-sectional study of 381 subjects from this population of mostly Pima Indians, glycated $\mathrm{Hb}\left(\mathrm{HbA}_{1 \mathrm{c}}\right)$ was highly specific and moderately sensitive in identifying subjects with diabetes (as diagnosed by OGTT). Diabetic subjects with normal $\mathrm{HbA}_{1 \mathrm{c}}$ had much lower fasting and 2-h post-load plasma glucose values than diabetic subjects with elevated $\mathrm{HbA}_{1 \mathrm{c}}$. Subjects with elevated $\mathrm{HbA}_{1 \mathrm{c}}$ and IGT had significantly higher fasting glucose values than the normal $\mathrm{HbA}_{1 \mathrm{c}}$ group with IGT [4]. One explanation for the fact that a sub-group of diabetic subjects have normal glycated $\mathrm{Hb}$ levels is that large post-load (or postmeal) excursions (e.g. causing 2 -h glucose values to fall in the diabetic range) have a minimal effect on the level of glycated $\mathrm{Hb}$ unless there is sustained hyperglycaemia.

In the present study, at follow-up there were fewer subjects who had either normal glucose tolerance and elevated $\mathrm{HbA}_{1 \mathrm{c}}$ or diabetes and normal $\mathrm{HbA}_{1 \mathrm{c}}$ than at baseline ( 15.1 vs $8.9 \%$ of subjects). These discrepant groups usually included borderline values; that is, normal glucose tolerance with $\mathrm{HbA}_{1 \mathrm{c}}$ values just outside the upper normal limit or glucose tolerance in the diabetic range with normal fasting glucose and 2-h glucose values only slightly above the $11.1 \mathrm{mmol} / \mathrm{l}$ cut-off for diagnosis of diabetes. As in our earlier study there were excellent correlations between $\mathrm{HbA}_{1 \mathrm{c}}$ and fasting and 2-h plasma glucose values both at baseline ( $r=0.91, r=0.88$, respectively) and at follow-up ( $r=0.92, r=0.91$, respectively). Because of the high prevalence of diabetes in this sample, this correlation may be higher than that observed in other studies.

Among subjects with a normal OGTT at the baseline examination, $\mathrm{HbA}_{1 \mathrm{c}}$ (when dichotomized into two groups) had no predictive value for the development of either IGT or diabetes. This finding is supported by the earlier findings of Modan et al. [9]. How- ever, among subjects with IGT, those with a high $\mathrm{HbA}_{1 \mathrm{c}}$ were at a significantly higher risk of developing diabetes during the follow-up than were those with a low $\mathrm{HbA}_{1 \mathrm{c}}$. Likewise, among subjects who already had diabetes at baseline, $\mathrm{HbA}_{1 \mathrm{c}}$ was significantly associated with the subsequent $2-\mathrm{h}$ glucose. Screening characteristics might vary in populations with different plasma glucose frequency distributions. However, among subjects with IGT, glycated $\mathrm{Hb}$ may help determine who will progress to diabetes.

Acknowledgements. We thank the members of the Gila River Indian Community for cooperation and participation and the staff of the Diabetes and Arthritis Epidemiology Section, NIDDK for conducting the examinations.

\section{References}

1. Dods RF, Bolmey C (1979) Glycosylated hemoglobin assay and oral glucose tolerance test compared for detection of diabetes mellitus. Clin Chem 25: 764-768

2. Simon D, Coignet MC, Thibult N et al. (1985) Comparison of glycosylated hemoglobin and fasting plasma glucose with two-hour post-load plasma glucose in the detection of diabetes mellitus. Am J Epidemiol 122: 589-593

3. Santiago JV, Davis JE, Fisher F (1978) Hemoglobin $A_{1 c}$ levels in a diabetes detection program. J Clin Endocrinol Metab 47: 578-580

4. Little RR, England JD, Wiedmeyer HM et al. (1988) Relationship of glycosylated hemoglobin to oral glucose tolerance: implications for diabetes screening. Diabetes 37: 60-64

5. Jovanovic L, Peterson C (1981) The clinical utility of glycosylated hemoglobin. Am J Med 70:331-338

6. Goldstein DE, Parker KM, England JD et al. (1982) Clinical application of glycosylated hemoglobin measurements. Diabetes 31 [Suppl 3]: 70-78

7. Gabbay KH, Sosenko JM, Banuchi GA et al. (1979) Glycosylated hemoglobins: increased glycosylation of hemoglobin A in diabetic patients. Diabetes 28: 337-340

8. Gonen B, Rubenstein AH, Rochman Het al. (1977) Haemoglobin A1: an indicator of the metabolic control of diabetic patients. Lancet II: 734-737

9. Modan M, Meytes D, Rozeman P et al. (1988) Significance of high $\mathrm{HbA} 1$ levels in normal glucose tolerance. Diabetes Care 11: $422-427$

10. The DCCT Research Group (1987) Feasibility of centralized measurements of glycated hemoglobin in the diabetes control and complications trial: a multicenter study. Clin Chem 33:2267-2271

11. World Health Organization (1985) Diabetes mellitus: report of a WHO study group. Technical Report Series 727 . World Health Organization, Geneva

12. Goldstein DE, Little RR, Wiedmeyer HM et al. (1986) Methods for quantifying glycosylated hemoglobins: high performance liquid chromatography and thiobarbituric acid colorimetry. In: Larner J, Pohl SI, Clarke WL (eds) Methods in diabetes research. Wiley, New York, pp 475-504

13. Ferrell RE, Hanis CL, Aguilar L et al. (1984) Glycosylated hemoglobin determination from capillary blood samples; utility in an epidemiologic survey of diabetes. Am J Epidemiol 119: 159-166

14. Manicardi V, Bonora E, Portioli I (1981) Comparison of glycosylated haemoglobin and OGTT in the screening of diabetes. Diabetologia 21: 301 (Abstract)

15. Bolli G, Compagnucci P, Cartechini MG et al. (1980) HbA1 in subjects with abnormal glucose tolerance but normal fasting plasma glucose. Diabetes 29:272-277 
16. Kesson CM, Young RE, Talwar D et al. (1982) Glycosylated hemoglobin in the diagnosis of non-insulin-dependent diabetes mellitus. Diabetes Care 5: 395-398

17. Orchard TJ, Daneman D, Becker DJ et al. (1982) Glycosylated hemoglobin: a screening test for diabetes mellitus? Prev Med 11:595-601

18. Lester E, Frazer AD, Shepherd CA et al. (1985) Glycosylated haemoglobin as an alternative to the glucose tolerance test for the diagnosis of diabetes mellitus. Ann Clin Biochem 22: 74-78

19. Modan M, Halkin H, Karasik A et al. (1984) Effectiveness of glycosylated hemoglobin, fasting plasma glucose, and a single post load plasma glucose level in population screening for glucose intolerance. Am J Epidemiol 119: 431-444
20. Flock EV, Bennett PH, Savage PJ et al. (1979) Bimodality of glycosylated hemoglobin distribution in Pima Indians: relationship to fasting hyperglycemia. Diabetes 28: 984-989

21. Hall PM, Cook JGH, Sheldon J et al. (1984) Glycosylated hemoglobins and glycosylated plasma proteins in the diagnosis of diabetes mellitus and impaired glucose tolerance. Diabetes Care 7: 147-150

22. Verillo A, de Teresa A, Golia R, Nunziata V (1983) The relationship between glycosylated haemoglobin levels and various degrees of glucose intolerance. Diabetologia 24:391-393

23. Dix D, Cohen P, Kingsley S et al. (1979) Glycohemoglobin and glucose tolerance tests compared as indicators of borderline diabetes. Clin Chem 25: 877-879 